\title{
Research on Online Shopping Demand of Chinese Elderly under the Background of Aging
}

\author{
Xiaoyu Wang1, Ling Jiang², * \\ ${ }^{1}$ School of International Economics and Trade, Anhui University of Finance and Economics, Bengbu, Anhui, China \\ ${ }^{2}$ School of Economics, Anhui University of Finance and Economics, Bengbu, Anhui, China \\ * Corresponding author: Ling Jiang (Email: j1567@sina.com)
}

\begin{abstract}
Firstly, this paper analyzes the main characteristics of China's elderly consumer market. Secondly, it analyzes the changes of the elderly consumer market from environmental and psychological factors. Thirdly, it analyzes the problems existing in China's online shopping market for the elderly. The study found that there are many problems in China's elderly market, including lack of pertinence of market products, complex operation, chaotic market order, many after-sales problems and so on. Finally, the following countermeasures and suggestions are put forward to promote the healthy development of the elderly consumer market: by expanding the development scope, creating the elderly model of online shopping platform, strengthening supervision and broadening sales channels, we can bring a more comfortable online shopping experience for the elderly group.
\end{abstract}

Keywords: Aging, Online shopping demand, Environmental factors, Psychological factor.

\section{Introduction}

At present, the problem of global aging has become a major population problem. According to the Research Report on the prediction of China's population aging development trend issued by the national Aging office, at present, 21 provinces (autonomous regions and cities) in China have become areas with an elderly population. In the 22 years from the third census in 1982 to 2004 , China's elderly population increased by an average of 3.02 million per year, with an average annual growth rate of $2.85 \%$, higher than the total population growth rate of $1.17 \%$. At the end of 2004, China's elderly population aged 60 and over reached 143 million, accounting for $10.97 \%$ of the total population.

At present, the spiritual needs of the elderly are not paid enough attention. Most investors only care about the food, housing, pension and other issues of the elderly. They rarely pay attention to the spiritual needs of the elderly group, ignoring that the elderly group also has the needs of respect, social needs and self realization.

The elderly group is a relatively large consumer group. According to the research in the 2017 elderly online consumption development report, the elderly group is growing continuously. However, at present, there are no relevant measures for the elderly, whether it is a large online shopping platform or a mobile app platform. In order to meet the needs of the majority of elderly groups, it is necessary to study this problem. According to the 13th five year national plan for the development of aging undertakings and the construction of pension system issued by the State Council in 2017, the national level now attaches great importance to the relevant needs of the elderly consumer market. Enriching the format of elderly care services, prospering the elderly products market, increasing the supply of elderly products and improving the scientific and technological content of elderly products are the development goal and direction of the elderly market [1]. During the 14th Five Year Plan period, China's elderly population will exceed 300 million and will move from mild aging to moderate aging. How to deal with this trend and do a good job in providing for the aged? The proposal of the CPC Central Committee on formulating the fourteenth five year plan for national economic and social development and the long-term goals for 2005 proposes to implement the national strategy to actively respond to population aging. The specific aspects of pension include: actively developing human resources for the elderly and developing silver economy. We will promote the coordinated development of the elderly care cause and the elderly care industry, improve the basic elderly care service system, develop inclusive elderly care services and mutual assistance elderly care, support families to assume the elderly care function, cultivate new forms of elderly care, build an elderly care service system coordinated by home community institutions and combined with medical care and health care, and improve the comprehensive supervision system of elderly care services. Under the influence of such an environment, it is very necessary to study the elderly market. Therefore, this paper studies the needs of the elderly for the current market, analyzes the problems existing in the elderly market, and puts forward corresponding solutions.

\section{Characteristics of the Elderly Consumer Market}

\subsection{Market Consumption Demand and Growth Is Fast and Has Great Potential}

In recent years, the consumption of the elderly online shopping consumer market has been increasing. According to the data of China Internet Information Center, in the first half of 2017, China's elderly Internet users grew rapidly, accounting for $4.8 \%$ of Internet users over 60 , an increase of 0.8 percentage points year-on-year. The growth of the number of elderly Internet users has directly led to the growth of online consumer demand. According to the calculation of the research group on pension consumption and pension industry development of the National Social Science Fund, the scale of China's elderly market will be 1.87 trillion yuan in 2015 and 48.52 trillion yuan by 2050 , which will develop rapidly at an annual growth rate of $9.74 \%$. The convenience of online shopping greatly facilitates children to buy necessities for 
their parents and expands the demand of the elderly market. In addition, the potential of this market is huge. Because many people in the elderly group do not shop online, their consumer market is a market goal worthy of development [2].

\subsection{Strong Feedback on Preferential Activities}

In terms of the group characteristics of the elderly, there will be strong feedback on preferential activities such as discounts and cash back, regardless of the degree of preference. According to jd.com, in the first three quarters of 2017 , the sensitivity of elderly users to promotion was $9 \%$ higher than that of the platform. High quality and cheap goods can arouse the interest of elderly consumers. Therefore, for the platform of the elderly market, there will generally be more preferential activities to stimulate the consumption desire of the elderly group.

\subsection{Strong Demand for Consumer Convenience}

Due to the inconvenience of activities and not being proficient in smart phones and other devices, the elderly groups will have a stronger demand for convenience. For the demand of convenience, there is an urgent need for online consumption platform to put forward corresponding solutions. The consumption feeling of the elderly group is closely related to the future consumption desire, so we should pay attention to the consumption convenience of the elderly group, so as to increase the consumption desire of the elderly group [3].

\subsection{There Is A Strong Demand for Communication Tools}

In recent years, due to the increase of empty nesters, the demand of the elderly for communication appliances has been growing. According to the data of the Ministry of civil affairs, in 2012, the number of empty nesters in urban and rural areas exceeded $50 \%$, and $70 \%$ in some large and medium-sized cities, including about 40 million left behind elderly people in rural areas, accounting for $37 \%$ of the rural elderly population. Therefore, the demand of the elderly group for communication is increasing. Therefore, online consumption platforms should meet the needs of the elderly.

\subsection{The Scope of Consumption Has Gradually Spread}

Jingdong data show that in the first half of 2017, the spatial distribution of elderly consumer groups showed "large coastal areas and small inland areas" Compared with the same period last year, the consumption of the elderly groups in the eastern region accounted for $64.2 \%$ of the country, and the number of consumer groups exceeded $60 \%$ of the country. Compared with the same period last year, the consumption of the elderly groups and the number of users in the eastern region decreased by 3.7 and 0.3 percentage points respectively, and the consumption of the elderly groups and the number of users in the central and western regions increased by 3.4 and 0.1 percentage points respectively This has something to do with economic development. The recent economic development is moving from coastal to inland, so the demand for online shopping in inland has been rising. More energy should be focused on the consumption demand of inland elderly groups to meet the needs of more elderly groups.

\subsection{The Consumption of the Elderly Tends to Be Fashionable and Younger}

In recent years, a video of four "fashion grannies" with an average age of 67 has attracted the attention and praise of many netizens and positive reports from mainstream media such as Xinhua news agency and people's network. "Fashion grannies" have a happy retirement life, which is obviously a positive social phenomenon. "Years have never lost beauty", "this is what I want to look like when I grow old." ... and other comments have become the mainstream under their videos. Although such elderly people are only a minority, they are enough to see the social attitude towards the pursuit of fashion for such elderly groups. Their profile is: a group of serious old, elegant and living grannies. They are inspired to bring the fashion attitude and culture of Chinese elderly people to the world stage [4]. This shows, to some extent, the change in the thinking of the elderly. With more and more products aimed at the elderly market, the mentality of some elderly people is becoming younger. According to JD data, in the first half of 2017, the consumption of beauty products by the elderly showed an explosive growth, 8.5 times the growth rate of such products on the platform. This is the current growth rate of the elderly The Chinese market is not the only major trend in the market. The economist reported that a company in Manhattan called "elderly planet exploration". In the center for the elderly, most elderly members have their own facebook accounts, online shopping and fitness coaches. Even if some elderly people are in their 80 s, they will still come here to participate in various courses, including how to start a business, how to use smart phones, how to book travel itinerary online, fill in the personal data needed for making friends online, etc. it can be seen that today's social hot spots are very important to the elderly Young people are not unheard of at all.

Therefore, the economist believes that if an enterprise or business wants to enter this emerging market, it needs more than financial support. I'm afraid the first thing to change is its inherent thinking pattern. The best-selling book "centenary life" co authored by Linda Graton and Andrew Scott, professors of London Business School The book once mentioned that the divorce rate of people over the age of 60 in the United States is twice that in 1990 and three times that in Britain. Compared with young people, the elderly are more willing to pay for valuable dating services, which has led to the birth of dating websites such as stitch and match.com for the elderly. It is reported that more than a quarter of members are between the ages of 53 and 73, and this The growth rate of members of one age group is faster than that of members of any age group. The economist specially pointed out that the new generation of elderly people, an emerging market, has its own characteristics. They generally do not regard themselves as elderly people and are often disgusted with advertisements specifically aimed at the elderly. This reflects the psychological change of the elderly to a certain extent [5]. Today's old people are more and more able to accept some new things that were not acceptable before, such as the "three pits" which is most popular with young people Generally speaking, the elderly do not think it is a fancy waste of money, but understand and have the desire to try. Therefore, the current market does not pay much attention to the elderly group, not because the group is not large enough or the consumption power of the group is not enough, but because they fail to get out of their own thinking pattern and do not 
think the elderly group can be right Younger commodities generate interest. While the shopping interest tends to be younger, the shopping preference of the elderly is also more inclined to domestic products. Domestic elderly commodity manufacturers have a clear and in-depth insight into market demand and rapid product iteration. The consumption of elderly commodities is still dominated by domestic brands. Therefore, it is hoped that domestic elderly product manufacturers can be aware of the spiritual needs of the elderly in this regard.

\section{Main Factors Causing Changes in the Consumption Market of the Elderly}

\subsection{Environmental Factors}

(1) Family environment. At present, Chinese families tend to be core and small, with an average family size of only 3.1 people. Therefore, the number of empty nesters has been increasing over the years, and the online platform greatly facilitates the need for children to buy necessities for their parents who do not live together. According to JD data, in the first half of 2017, the majority of elderly commodity buyers were 26-35 years old, with a population coverage rate of 4 $6.2 \%$, accounting for $46.7 \%$. This also reflects the separation of purchase and use in the online elderly consumer market. In addition, due to the influence of Chinese traditional ideas, children take more care of their parents and often buy necessities needed by their parents. This is one of the reasons for the change of the silver hair market [6].

(2) Living environment. With the increase of quality of life in recent years, the elderly group is more and more concerned about their health and quality of life. In terms of medical and health care products, in the first half of 2017, the elderly commodity market was dominated by medical and health care products, accounting for $25.8 \%$ of sales, and maintained a sustained and rapid growth trend, with a year-on-year increase of $438.2 \%$, contributing $55.1 \%$ to the growth of elderly commodity sales In addition to paying attention to health, the elderly group is also pursuing spiritual needs. Among the 14 key commodities, morning clothes, square dance sound and elderly milk powder occupy an important market share, reflecting the elderly group's attention to health and social networking. In addition, the enrichment of square dance and other life activities also drives the sales of relevant products.

(3) Economic environment. Because of China's economic development in recent years, "what you eat" The era of has passed, and the elderly groups are more and more willing to spend money on happiness and health for themselves. People have more and more savings, which promotes the consumption of the elderly groups. In such an economic environment, not only the young people, but also the elderly can meet their own certain desires. The rapid development of the economy makes these gratifications easy Therefore, the consumer market of the elderly group can be further expanded. It can be said that economic factors are the most direct and important factor leading to the growth of the elderly consumer market.

\subsection{Psychological Factors}

The main consumers of online shopping are the young elderly, so they will consume because they please themselves in the process of consumption. Under the action of such psychological factors, it indirectly affects the consumption desire of the elderly group. According to Maslow's "five levels of needs". Theory, that is, physiological needs, safety needs, social needs, respect needs and self realization needs. Needs generate motivation, and consumer purchase motivation is formed by the combination of consumers' internal needs and external stimuli to generate a driving force. According to the current situation, physiological needs and safety needs have been met, and because of the relationship of empty nesters, Social needs and the need for self realization are particularly important. First, social needs. In recent years, the elderly like to go to the square to dance and play Tai Chi. These are the social activities that the elderly need, and the demand for related goods naturally moves. Second, respect needs. Because of the changes in economy and psychology, the elderly also need to buy Respect from others. Therefore, more and more attention is paid to display consumption such as make-up and clothing. Among the elderly commodities, the sales of clothing and underwear account for the largest proportion, reaching $24.3 \%$. Third, the need for self realization. The elderly group also has a certain need for self realization. In recent years, the learning desire of the elderly group has become higher and higher, and various online education institutions have begun to have more and more opportunities Elderly learning groups. These are influenced by psychological needs [7].

Under the influence of external environmental factors and internal psychological factors, the scope of the elderly market is gradually expanding, the scale of elderly consumption is expanding rapidly, the elderly consumption demand is improving to high quality, the elderly consumption content is more diversified, and the elderly consumption mode is more extensive. The survey of the National Commission on aging shows that the number of elderly tourists accounts for more than $100 \%$ of the total number of tourists in China every year Over $20 \%$, the food consumption market has become the second largest tourism market after the middle-aged tourism market. This is a relatively big breakthrough in the life consumption market. In this rapidly changing mobile Internet era, many elderly people choose to take this convenient Internet Express. The frequency of the elderly using the network is gradually increasing, and the consumption thoughts of the elderly also follow constantly updated. It has gradually changed from "shopping" to online shopping. Under the background of consumer demand, the consumer demand of the elderly is changing from basic living needs to improving living standards [8].

\section{Problems in the Online Shopping Market for the EIderly}

\subsection{Market Products Lack Pertinence}

At present, several major domestic shopping platforms lack pertinence for the commodities in the elderly market. Compared with more than a dozen product classifications of young shopping groups, the classification of elderly commodities is very few. Taking the most widely used shopping platform, the classification of items obtained by searching the elderly is only the classification of middle-aged and elderly pants, clothes, etc., without detailed style classification. The elderly group is not very familiar with shopping platforms such as app. The lack of detailed product classification undoubtedly weakens the shopping experience of the elderly group, and few businesses can understand the real needs of the elderly group, and rarely push the products 
needed by the elderly group in time. This lack of targeted online market can not timely respond to the real needs of the group, and it is difficult to control the real preferences of elderly consumers.

\subsection{Complex Operation}

Through certain interviews and questionnaires, most elderly people can't control the current too fancy online shopping platform, unclear search columns, useless and complicated recommendations, complex shopping traps, etc., which are difficult for elderly groups to control. Such a situation can not explore the potential of this market. In addition, there are many unnecessary operations in the order placing process and refund process. For example, in the return process, filling in the return reason and booking the return time can actually be simplified to the greatest extent, which can reduce the uncertainty of the elderly group about online shopping and stimulate the consumption of the elderly group to a certain extent.

\subsection{Market Disorder}

In terms of shopping for the elderly, the market lacks overall planning, so lack of supervision and chaotic market order are common. Especially for the elderly health care products industry, because its target group is easy to trust and has no prevention and other characteristics, this market has become a profiteering market, with multi head management and random license issuance. For manufacturers and sellers, there is only approval and no supervision. At the same time, due to the lack of unified - industry standards and classification, the fish and eyes of products in the market are mixed, and even some illegally produced low-quality products flow into the market. Moreover, the production and sellers blindly exaggerate the use of goods and mislead elderly consumers. The industry production is disordered and the market order is disordered. How many health care functions does the health care product have? The national institution does not need to carry out relevant verification, but only needs the review experts to carry out theoretical analysis on the submitted materials.

\subsection{There Are Many After-sales Problems and Poor Service Awareness}

In addition to the complex platform problems, the problems after return are also complex problems. Many return platforms reject consumers' demand for return just because merchants refuse to return goods, and the path of negotiating with the platform is often complex and lengthy. It is necessary to put forward their demand for return step by step. Many times, negotiating with merchants is only the automatic reply of robots. The elderly naturally do not call to negotiate, so they often adhere to the idea of "one thing is better than one thing less", Let it pass. In addition, the return process is also very troublesome. You need to contact the return stop or find the return site yourself, which is far from the purpose of online shopping for the elderly.

\section{Countermeasures and Suggestions}

\subsection{Explore Product Demand and Expand the Breadth of Product Development}

Focus on supporting some enterprises of elderly products, and create favorable conditions for the development of the elderly market by issuing corresponding preferential policies.
Support the development of these enterprises by reducing corresponding taxes, credit and other links, and increase support. Try your best to understand the actual needs of the elderly. You can go deep into the elderly group and explore the business needs of the elderly group through questionnaire survey and community visit activities. Make full use of big data technology to analyze the commodity demand characteristics of the elderly in different regions, so as to develop corresponding elderly commodities, subdivide the elderly market and enrich the elderly products market. Recommend the goods that the elderly may be interested in according to the region and group, and develop the market of the elderly goods to the greatest extent, so as to make the online shopping experience of the elderly better [9].

\subsection{Corresponding Platform Development Model}

You can refer to the "youth model" of some video websites, and the online shopping platform can also develop the corresponding "elderly model". In this mode, everything is simplified to reduce unnecessary tools that are not conducive to the consumption of the elderly. The font can be adjusted arbitrarily. The matters needing attention can be broadcast by voice, the shopping steps can be simplified, there are corresponding videos to teach where there are problems, and there can be 24-hour manual customer service to answer questions, solve doubts, recommend products, etc, Solve various problems in shopping for the elderly. This model is specifically aimed at the elderly group. The source of goods should ensure safety to a great extent, build a professional corresponding team, reduce the risk of buying fake goods and drugs for the elderly group, and think carefully for the elderly group [10].

\subsection{Strengthen Supervision and Optimize the Consumption Environment}

Relevant state organs, departments and industry associations shall clarify their responsibilities, strengthen market supervision, and establish a perfect market system and product certification system. Severely crack down on the production of enterprises without production qualification, resolutely put an end to the flow of unqualified and inferior products into the market, always pay attention to and prevent acts that undermine the market order such as false publicity, making and selling fake products, standardize the development of the elderly consumer market, and safeguard the rights and interests of the elderly consumer groups from all links of production, circulation and sales. Strengthen the intellectual property protection of aging products, protect registered trademarks and patented products, and earnestly safeguard the interests of relevant enterprises, so as to encourage enterprises to boldly carry out production.

\subsection{Expand Sales Channels and Improve Supporting Facilities and Services}

Actively develop the elderly commodity stores. Based on the original counters in the elderly shopping malls, adopt the chain monopoly mode to purchase and sell uniformly, so as to achieve low-cost and rapid development. Learn from the experience of pregnancy and infant monopoly, collect the commodities with elderly characteristics in one store to meet the one-stop shopping needs of elderly commodities. In terms of distribution channels, we will further optimize the layout of outlets, improve the construction of supporting facilities 
and service facilities, and improve the level of sales, display, guidance, after-sales and other related services. The choice of store location should be as close to the elderly consumers as possible, distributed in residential areas where the elderly are concentrated or where the transportation is convenient. Fully consider the psychological and physiological characteristics of the elderly group, create a targeted column for the online consumption of the elderly group, and make barrier free design for the web page, so as to provide full convenience for the elderly group to browse and order. Guide enterprises to launch apps tailored for elderly users, and further develop and expand elderly consumption in more fields such as goods and services.

\section{References}

[1] Zhong Jing. Reveal the new trend of elderly consumption [N]. China geriatrics daily, 2018-01-11(003).

[2] $\mathrm{Hu}$ JieFei. Silver economy welcomes favorable policies [N].China business times, 2021-12-01(003)

[3] Li Xinghui. Study on Influencing Factors of consumption expenditure of urban elderly population in China [D]. Yanbian University, 2021.
[4] $\mathrm{Xu}$ Guyu, Wang Yibo, Wang Yansong, Chen Qifei. Optimization path of silver consumption industry under the background of Internet [J]. Jiangsu business theory, 2021 (10): 3-9.

[5] Wang Shaohui, Li Fufu. Consumption structure, demand characteristics and behavioral decision-making of Chinese elderly groups [J]. Beijing Social Sciences, 2021 (08): 119-128.

[6] Ma Yanjuan. Focus on the needs of the elderly and provide high-quality, convenient and warm-hearted services [J]. China social work, 2021 (23): 36-37.

[7] Duan Yu, Gao Lu. Pension market opportunities under population aging $[\mathrm{N}]$ China Labor and social security news, 2021-07-07(006).

[8] Yang Xiaoze. Research on the spiritual needs of the elderly under the background of longevity economy [J]. Journal of Xinjiang Radio and Television University, 2021,25 (02): 56-60.

[9] Lu Ping. Perceive the impact of product innovation on the purchase intention of aging smart products [D]. Dalian University of technology, 2021.

[10] Yang Hangfei. Analysis of China's aging consumption trend under the background of population aging [D]. Hebei University, 2020. 